\title{
LXXI. New method of congealing water in a vacuum
}

\section{M.T. Grothuss}

To cite this article: M.T. Grothuss (1820) LXXI. New method of congealing water in a vacuum , Philosophical Magazine Series 1, 56:272, 436-440, DOI: 10.1080/14786442008652440

To link to this article: http://dx.doi.org/10.1080/14786442008652440

曲 Published online: 29 Jul 2009.

Submit your article to this journal ๘

Џll Article views: 2

Q View related articles $\sqsubset$ 
within the limits mentioned by him. This induced me to make a calculation of the time of beginning for Leighton; and I was surprised to find the time differ more than four minutes from the time given by so good an observation. I take it for granted, thar Mr. B. has been misled by the equation of time in the Nantical Almanae being marked Add, instead of Sul.

I hope, if this has been the case, Mr. B. will have the goodness to give the times thus corrected in the same explicit manner in which he sent you his former observations.

In a calculation of this eclipse by Mr. MacGregor, noticed in your last Magazine, and upon which you have bestowed such merited enconiums, I have observed that he has made the equation of time rather too great; but his 14 th and 3 Ist equations of longitude, being respectively $0^{\prime \prime} \cdot 78$, and $0^{\prime \prime} \cdot 9$ too small, will very nearly balance the error in the equation of time.

Your inserting the above will oblige, Aberdeen, Nov. 10, 1820.

Sir, your most obedient servant,

GEo. InNes.

LXXI. New Method of congealing Water in a Vacuum. By M. T. Grothuss *.

$\mathbf{T}_{\text {HE beautiful discovery of Professor Leslie on the artificial }}$ congelation of water has successively engaged the attention of many learned philosophers and chemists. They have sought to give to this discovery a more extended application, in order to convert it to some great object of utility; and already their labours have led to the discovery of some particular results which night otherwise have remained long concealed. In the mean time it must be useful to make known all the facts connected with this discovery; and I am therefore induced to publish the result of an experiment by which I effected the congelation of water promptly and with the greatest facility.

Into a metal vase hall filled with water, 1 poured very gently an equal quantity of ether, so that no mixture might take place of the two liquids. The vase was placed under the receiver of an air-pump, which was so fixed upon its support as to remain quite steady when the air was pumped out. At the first strokes of the piston the ether becume in a state of ebullition; it was evaporated totally in less than a minute, and the water remained converted into ice. I made this experiment for the first time at Mittau, in all apartment the temperature of which was $16^{\circ} \mathrm{R}$.

- Annales Gèuérales des Sciences Physiques. By MM. Van Mons, \&c.

LXXII. Cal- 


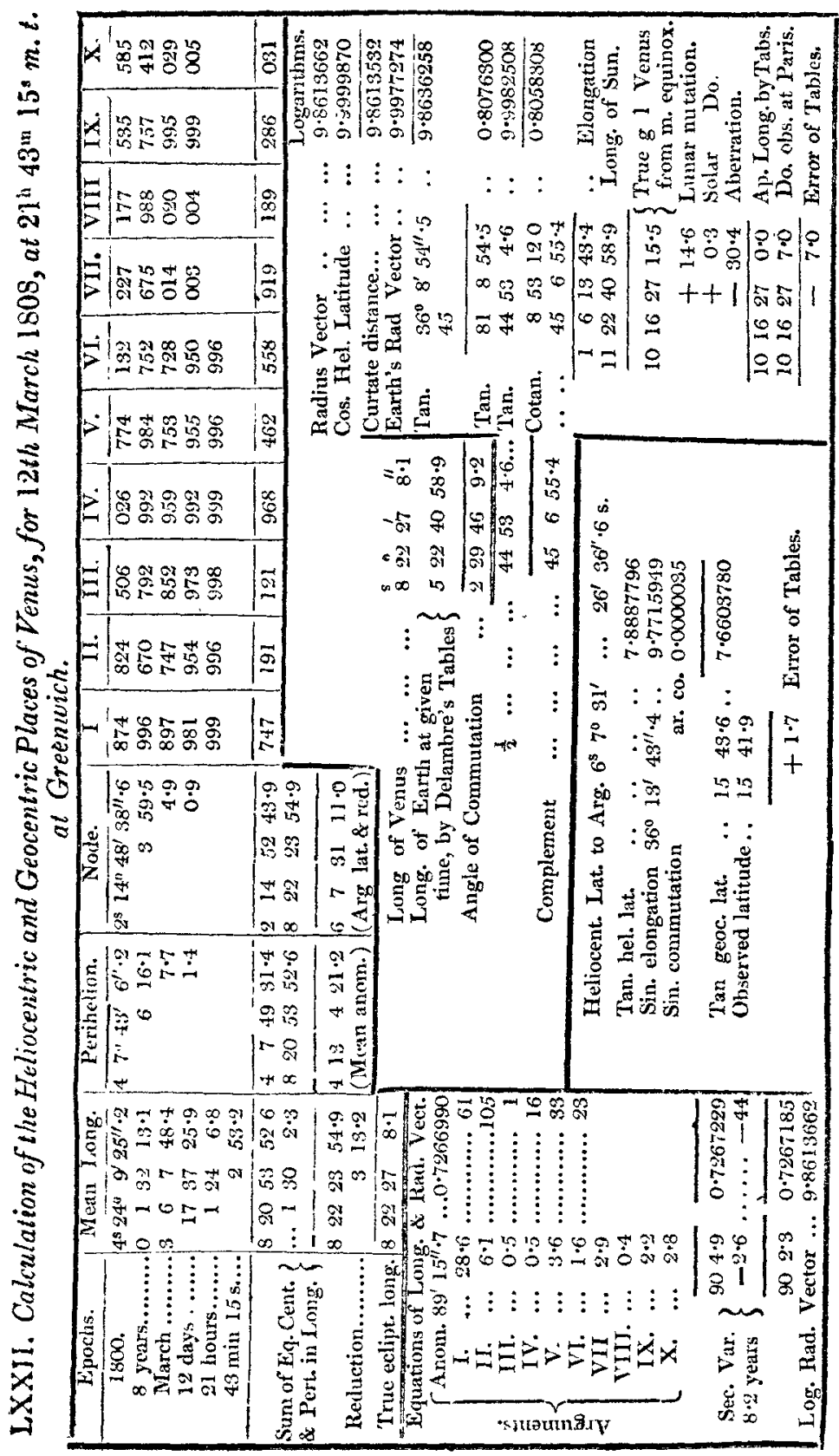


Precepts for the Application of the NEw Tables of Venus, contained in a preceding Part of this Volume, illustrated by an Example. By the Editor of the Tatles.

The following concise precepts will apply, with very little alteration, to other planetary tables coustructed according to the improved arrangement.

\section{To find the Heliocentric Longitude and Latitude.}

1. From Tab. II. take out the epochs of the mean longitude, perihelion, and node, with the ten arguments of perturbation, and place them in an horizontal line. But if the given year be not found in that Table, take the nearest preceding it *, and add underneath the motions from Tab. I. for so many years as the epoch taken from Tab. II. precedes the given year.

2. Under these, write down successively the mean motions for the given month, day, hour, minute, and second, frum Ta. bles III. IV. and V.

3. Add together the numbers in the several columns; rejecting in the longitude, perihelion, and node, 12 signs, and in the arguments of perturbation, 1000 , or any multiples thereof respectively, if they occur.

4. From the tabular mean longitude thus found (increased by 12 signs if necessary) subtract the longitude perihelion; the remainder will be the mean anonaly, with which enter ' $\mathrm{Tab}$.VI. (making proportion for the minutes and seconds), and take out the equation of the centre, which set down apart.

5 . With the ten several arguments of perturbation enter $\mathbf{~ F a - ~}$ ble VII. and take out the corresponding equations, which write down surecessively under the quantity found by the last precept, and add the whole together. Then recur to Tab. Vl. take from it the secular variation of the elliptic equation, and apply the same according to its sign to the sum just found: observing that for a period anterior to 1800 , the sign of the Table must be changed.

6 . Add the corrected sum of the equations to the mean longitude, and from the quantity thus obtained (increased by 12 signs if necessary) sultract the longitude of the node, the remainder is the argument of latitude and of reduction.

7. With the last-mentioned argument take out from Tab. X. the reduction, which being added to the corrected longitude before found, gives the planet's true heliocentric longitude on the ecliptic reckoned from the mean equinox.

* Except 1790 , which, not being a Julian Bissextile, cannot be used in conjunction with Tab. 1 .

8. The 
8. The same argument applied to Table XII. obtains the planet's heliocentric latitude *.

\section{To find the Radius Vector.}

9. With the mean anomaly found by precept 4 , enter Table VIII. for the elliptic radius vector; underneath which write the several corrections of the same taken from Tab. IX. by means of the six first arguments of perturbation. To the sum of the seven quantities, apply the secular equation, and the result is the true radius vector, corresponding to the mean distance 0.72333166 .

\section{To find the Geocentric Longitude and Latitude.}

10. Calculate the earth's longitude and radius vector for the given time from the solar tables.

11. To the logarithm of the planet's radius vector, add the logarithmic cosine of its heliocentric latitude, either from Tab. XI. or from the common trigonometrical tables; the sum, rejecting 10 from the index, will be the logarithm of the planet's curtate distance.

12. Then, in the plane triangle formed by the sun, earth, and planet's ecliptic place, we have given two sides, viz. the earth's radius vector, and the planet's curtate distance, with their included angle, called the angle of commutation. This latter is found by subtracting the earth's longitude from that of the planet (increased by 12 signs if necessary). From these data the other two angles are found by the operations of trigonometry $\uparrow$. The angle at the earth is called the elongation, and, in the case of an inferior planet, it is always the least of the two.

13. When the angle of commutation is greater than six signs, add the elongation to the sun's longitude, the sum is the planet's true geocentric longitude reckoued from the mean equinox : but if the angle be less than six signs, the elongation is to be subtracted.

14. Add together the log. $\tan$. heliocentric latitude, log. sin.

* In the Introdnction to the original Tables, the secular variation of greatest latitude is stated to be $-7^{\prime \prime} \cdot 24 \mathrm{cos}$. inclin. but in the Tubles themselves the co-efficient seems to be $+8^{\prime \prime} \cdot 4$. On account of this discordance, and the smallness of the correction, it was thought proper in Tab. XII. to omit altogether the columa of secular variation.

+ There are two formulæ adapted to the solution of this case. The one employed in the following example, has generally been adopted in calculations of this kind; but since the introduction of equations of perturbation into Astronomical Tables has rendered it necessary to give the radius vector in natural numbers instead of logarithms, perhaps the more common formula would now be found preferable in practice. In that case, however, there must be substituted for Table XI. one of double entry for obtaining the eutate distance in natural numbers. 
elongation, and arithmet. comp. log. sin. commutation, the sum of these three logarithms, rejecting 10 from the index, is the log. tan. geocentric latitude.

Corrections for the Original Quarto Talles, which are not noticed in the List of Errata.

$\begin{array}{llllll}\text { Page } 1 & 1819 \text { long. aphelion, read } 10 & 8 & 57 & 59 \cdot 3 .\end{array}$

$1 \quad 1820 \ldots 1085846.4$.

11890 The mean long. aphelion, and node, are all for 1900 , though in page 2 the numbers are right.

21809 Arg. I. read 245.

$21840+\ldots 54$.

4200 years, Arg. VI. read 594.

5 Motions of aphelion and node for months are incorrect.

61 day, aphelion, read $0 \cdot 1$.

948 min. read 3123.

10 Arg. $2^{\text {s. }} 8^{\circ}$. read $4336 \cdot 1$.

21 Tal. XXI. read $(2 \mathrm{~V}-\mathrm{M})$.

$21-X X I 11$. Arg. 280, read 26.

$21-X X I V$. - 500 to 600 , sign + .

25 Change places with the arguments 4521 and 4722 .

Corrections for the Reprint in the Philosophical Magazine.

Introduction. For Table X. read XII.

Tab. I. 4 years, Arg. VIII. for 404 read 494 .

II. 1813, Mean Longitude, for $14 \cdot 6 \mathrm{read} 14.5$.

- X. Arg. $0^{\mathrm{s}} .14^{\circ}$, and $2^{\mathrm{s}} .16^{\circ}$, for 235.5 read $235 \cdot 2$.

- XIII. Change places with the arguments 4521 and 4722.

VI. (Title) for $1820 \mathrm{read} 1800$.

\section{The Arctic Expeditim.}

Wi r h our present Number we have given a Map of the discoveries of Captain Parry in the Polar sea. The official aceount of the voyage has not yet made its appearance, and we have but little to add to the statements laid before our readers in our last Number (p. 383). The subjoined particulars, among which are a few not before noticed, are from an officer on board one of the ships:-

ON the 11 th of Mav 1819 the Hecla and Griper left England. In the middle of June they first fell in with ice; and at the latter end of that month they were heset by it, while making for the west coast of Davis's Straits. After some little time the ships were liberated, and steered northward along the edge of the ice, which 